\title{
Editorial
}

\section{The Socioeconomic Status of Subjects: A Prominent Feature Contributing to the Phenotypical Approach to COPD}

\author{
R.W. Dal Negro ${ }^{a, b}$ \\ a Lung Department, ULSS22 Regione Veneto, Orlandi General Hospital, and ${ }^{\mathrm{b}}$ Centro Nazionale Studi di \\ Farmacoeconomia e Farmacoepidemiologia Respiratoria - CESFAR, Verona, Italy
}

The current understanding of chronic obstructive pulmonary disease (COPD) is still incomplete, and several factors contribute to its overall impact in both industrialized and developing countries.

The epidemiology of COPD has been investigated extensively over the last decades and the role of many causative and predisposing factors have been focused on, though most attention has usually been concentrated on the specific function of some behavioral (i.e. tobacco smoke), clinical (i.e. respiratory signs, lung function), and biological (i.e. age, gender, infections, genetics) determinants of the disease [1].

COPD is a complex disease characterized by numerous pulmonary and extra-pulmonary components which contribute significantly to its heterogeneity in terms of clinical manifestations, physiological pictures, radiological imaging, response to therapeutic treatments, morbidity, and survival. Moreover, the complexity of the disease cannot be represented exhaustively by a single parameter, and integrated indices considering different factors simultaneously have been progressively proposed and suggested as being much more sensitive, though they still mainly stem from clinical and physiological peculiarities [2].
Although the role of socioeconomic status in COPD has been poorly investigated when studying the determinants of respiratory health in 'real life', lower education levels and economic status have been presumed to lead to a higher probability of suffering from this disease [3-5]. Actually, these two conditions tend to work as main determinants of patients' future because they usually lead to poorer housing and nutritional intake, a higher incidence of respiratory infections (particularly in childhood), a higher prevalence of smoking, a higher probability of accepting disadvantaged jobs, etc. [6]. In other words, the lower the start level the steeper the way to the finish line.

In this issue of Respiration, Miravitlles et al. [7] specifically investigated and focused on this peculiar aspect and clearly assessed how both the socioeconomic and the educational status of COPD subjects can affect (or can have affected) primarily their quality of life and other related outcomes in real life (i.e. an early diagnosis, early treatment, awareness of the disease, etc.). This paper also showed that the socioeconomic status (e.g. the individual's educational level and income) represents an independent factor which proves able to substantially impair the health status of COPD patients also in a public heath system oriented toward the welfare model.

\section{KARGER}

Fax +4161306 1234

E-Mail karger@karger.ch

www.karger.com
(C) 2011 S. Karger AG, Basel

0025-7931/11/0825-0400\$38.00/0

Accessible online at:

www.karger.com/res
Dr. Roberto W. Dal Negro

Lung Department, ULSS22 Regione Veneto

Orlandi General Hospital, Via Ospedale, 2

IT-37012 Bussolengo (Italy)

Tel. +39045676 9193, E-Mail rdalnegro@ulss22.ven.it 
In particular, the data of this paper should be regarded with increasing interest in present times, when COPD is basically going to be interpreted according to an ever increasing number of phenotypic determinants $[8,9]$. Actually, together with other relevant attributes (such as symptoms, imaging, and lung function), also the assess- ment of the socioeconomic status of individuals should enter the list of those basic findings, allowing a more complete definition of factors leading to COPD and predicting the effects of management, the prognosis, and also costs of the disease according to a novel and peculiar phenotypic root.

\section{References}

1 Viegi G: Epidemiology of chronic obstructive pulmonary disease (COPD). Respiration 2001;68:4-19.

$\checkmark 2$ Celli BE, Cote CG, Marin JM, Casanova C, Montes de Oca M, Mendez EA, Pinto Plata V, Cabral HJ: The body mass index, airflow obstruction, dyspnea, and exercise capacity index in chronic obstructive pulmonary disease. N Engl J Med 2004;350:1005-1012.

$>3$ Prescott E, Lange P, Vestbo J: Socioeconomic status, lung function and admission to hospital for COPD: results from the Copenhagen City Health Study. Eur Respir J 1999;13: 1109-1114.
-4 Thorn J, Bjorkelund C, Bengtsson C, Guo X, Lissenr L, Sundh V: Low socio-economic status, smoking, mental stress and obesity predict obstructive symptoms in women, but only smoking also predicts subsequent experience of poor health. Int J Med Sci 2006;4: 7-12.

5 Kanervist M, Vasankari T, Laitinen T, Heliovaara M, Jpusilathi P, Saarelainen S: Low socioeconomic status is associated with chronic obstructive airway disease. Respir Med 2011;105:1140-1146.

6 Bousquet J, Dahl R, Khaltaev N: Global alliance against chronic respiratory disease. Allergy 2007;62:216-223.

7 Miravitlles M, Naberan K, Cantoni J, Azpeitia A: Socioeconomic status and health-related quality of life of patients with chronic obstructive pulmonary disease. Respiration 2011;82:402-408.
8 Marsh SE, Travers J, Weatherall M, Williams MV, Aldington S, Shirtcliffe PM, Hansell AL, Nowitz MR, McNaughton AA, Soriano JB, Beasley RW: Proportional classification of COPD phenotypes. Thorax 2008;63:761767.

9 Han MK, Agusti A, Calverly PM, Celli BE, Criner G, Curtis JL, Fabbri LM, Goldin JG, Jones PW, Make BJ, Rabe KF, Rennard SI, Sciurba FC, Silverman EK, Vestbo J, Washko GR, Wouters EF, Martinez FJ: Chronic obstructive pulmonary disease phenotypes: the future of COPD. Am J Respir Crit Care Med 2010;182:598-604. 